\title{
Simple Spectrophotometric Methods for Determination of Tenofovir Fumarate and Emtricitabine in Bulk Powder and in Tablets
}

\author{
Mohammad H. AbdelHay, Azza A. Gazy, Rasha A. Shaalan, and Heba K. Ashour \\ Pharmaceutical Analytical Chemistry Department, Faculty of Pharmacy, University of Alexandria, Elmessalah 21521, \\ Alexandria 21521, Egypt \\ Correspondence should be addressed to Rasha A. Shaalan; rasha_shaalan@yahoo.com
}

Received 21 May 2013; Accepted 3 July 2013

Academic Editor: Lu Yang

Copyright (C) 2013 Mohammad H. AbdelHay et al. This is an open access article distributed under the Creative Commons Attribution License, which permits unrestricted use, distribution, and reproduction in any medium, provided the original work is properly cited.

\begin{abstract}
Two simple and selective methods were developed for the simultaneous determination of tenofovir fumarate (TEN) and emtricitabine (EMT) in combined tablets. The first method involves the application of first derivative spectrophotometry where the first derivative amplitudes were measured at $298.5 \mathrm{~nm}$ for determination of EMT in presence of TEN. The second method involves first derivative of ratio spectra spectrophotometry where the amplitudes at $251.5 \mathrm{~nm}$ have been used for quantitation of TEN in the presence of EMT. Different variables affecting each method were carefully investigated and optimized. Reliability and analytical performance of the proposed methods, including linearity, range, precision, accuracy, detection, and quantitation limits, were statistically validated. The methods were successfully applied for the determination of EMT and TEN in laboratory-prepared mixtures and in their combined tablets.
\end{abstract}

\section{Introduction}

Antiviral drugs development has become a very active area in the last decade, especially with the challenges of AIDS, hepatitis, and avian and swine flu epidemics. The antiviral drugs are used in the treatment of viral infections. They may also be used to provide protection, usually for a brief period only, against infection. There is little evidence that these compounds affect latent or nonreplicating virus. Nonspecific symptomatic and supportive treatment is also important in the management of viral infections. Tenofovir disoproxil fumarate (TEN) is 9-[(R)-2 [[bis[[(isopropoxycarbonyl)oxy]methoxy] phosphinyl] methoxy] propyl] adenine fumarate [1] (Figure 1). It belongs to a class of antiretroviral drugs known as nucleotide analogue reverse transcriptase inhibitors (NRTIs), which block reverse transcriptase, an enzyme crucial to viral production in HIV-infected people $[2,3]$.

Emtricitabine (EMT), 4-amino-5-fluoro-1-[(2R,5S)-2-(hydroxymethyl)-1,3-oxathiolan-5-yl]-1,2-dihydropyrimidin-2one [1] (Figure 1), works by inhibiting reverse transcriptase enzyme that copies HIV RNA into new viral DNA. It can help lower the level of HIV in the patient's body and can indirectly increase the number of immune system cells. EMT is indicated in combination with other antiretroviral agents for the treatment of HIV and HBV infection in adults $[2,3]$. Being relatively recent drugs, TEN and EMT are not official in BP 2010 or USP 2011.

TEN is formulated in binary mixture with the reverse transcriptase inhibitor emtricitabine (EMT) to prevent HIV from altering the genetic material of healthy T cells. Combining the two drugs in one tablet helps in reduction of the pill burden and increases the compliance with antiretroviral therapy.

Simple spectrophotometric techniques have been published involving determination of TEN by direct methods $[4,5]$, derivative calculation [6-8]. Other spectrophotometric methods published include colorimetric assay using various derivatizing reagents [9-12].

HPLC has great application in the therapeutic drug monitoring of TEN in different biological samples [13-19]. Almost all HPLC assays depend on mass spectrometric detection of 

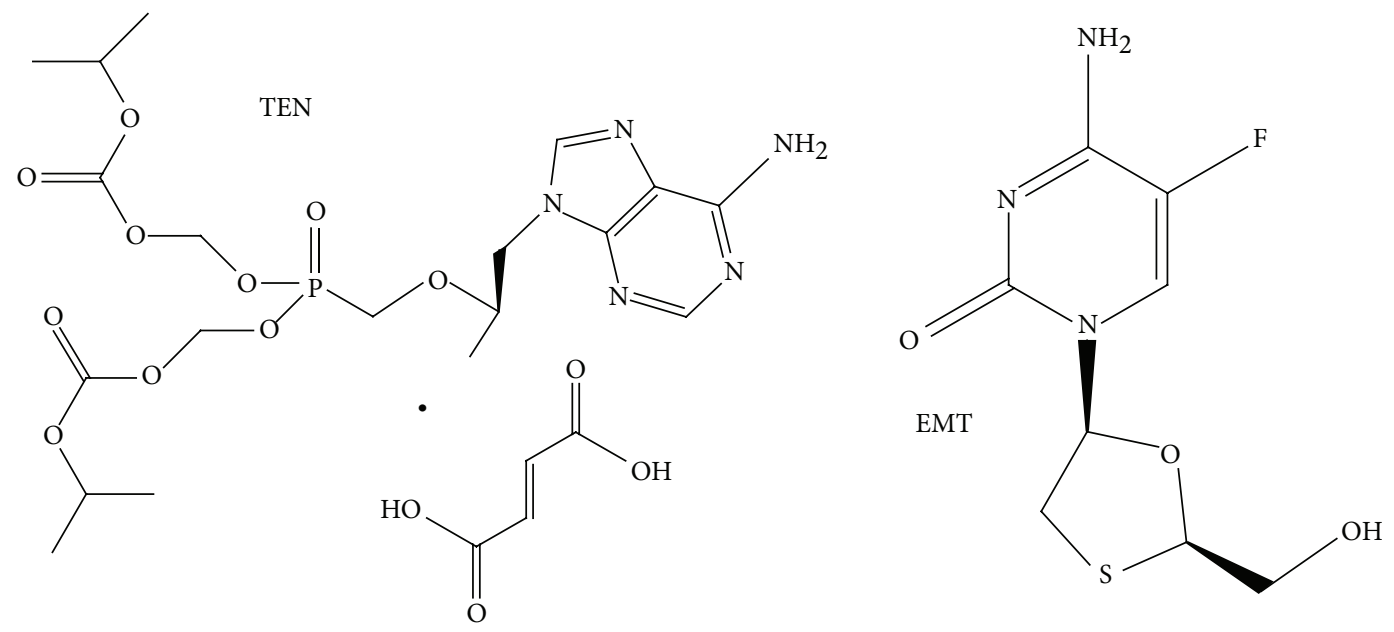

FIGURE 1: Structures of tenofovir disoproxil fumarate (TEN) and emtricitabine (EMT).

TEN. Only one method made use of UV for detection of TEN at $259 \mathrm{~nm}$ [15]. Other HPLC methods are applied for assay of TEN in bulk powder and in pharmaceutical preparations [20-22].

The literature reveals that HPLC is the most common technique for the assay of EMT. Several HPLC methods aiming at the determination of EMT in plasma were found in the literature depending on either UV detection $[23,24]$ or fluorimetric detection [25]. The quality control of pharmaceutical products could be monitored using a published HPLC methodology based on C18 column and UV detection [26]. Few LC methods were developed for determination of EMT and its related compounds [27-29]. The analytical behavior of EMT in gas chromatography and polarography [30] was also studied.

Several HPLC methods were found in the literature for the assay of TEN/EMT mixture [31-34]. Detection of both drugs in these methods was achieved either depending on UV detection $[31,33,34]$ or mass spectrometry $[32,35,36]$. The reported methods were applied for the simultaneous determination of TEN and EMT in plasma $[31,32,35,36]$ or in pharmaceuticals $[33,34]$. Two spectrophotometric methods were published for the assay of the binary mixture in tablets $[37,38]$. Only one HPTLC method was found for the assay of the mixture in tablets using chloroform and methanol $(9: 1)$ as a mobile phase and UV detection at $265 \mathrm{~nm}$ [39].

The literature reveals few methods for the simultaneous assay of TEN/EMT mixture with other antiviral drugs as lamivudine and/or zidovudine [40, 41] and lopinavir [42] using HPLC technique.

\section{Experimental}

2.1. Instrumentation. Spectrophotometric measurements were performed using a Specord S600 spectrophotometer, associated with Win Aspect software version 2.3 (Analytik Jena AG, Germany).
2.2. Materials and Reagents. Authentic samples of tenofovir disproxil fumarate (TEN) and emtricitabine (EMT) were kindly provided by Gilead Pharmaceuticals, USA. Truvada tablets are labeled to contain $300 \mathrm{mg}$ tenofovir and $200 \mathrm{mg}$ emtricitabine (Gilead Sciences Inc., Canada).

Stock solutions of either TEN or EMT $1000 \mu \mathrm{g} \mathrm{mL}^{-1}$ were prepared in high purity distilled water and stored refrigerated at $4^{\circ} \mathrm{C}$.

\subsection{General Procedure and Construction of Calibration Curves}

2.3.1. First Derivative Method $\left({ }^{1} D\right)$. Aliquots from the EMT stock standard solution $\left(1000 \mu \mathrm{g} \mathrm{mL}^{-1}\right)$ equivalent to $0.5-$ $40 \mu \mathrm{g} \mathrm{mL}^{-1}$ were transferred into a set of $10 \mathrm{~mL}$ volumetric flasks. The solutions were diluted to volume with distilled water and mixed well. The absorption spectra were recorded against distilled water as blank in the wavelength range 200$300 \mathrm{~nm}$ and stored. The first derivative spectra were calculated (number of points $=25$ ), and the absolute values of ${ }^{1} \mathrm{D}$ amplitude at $298.5 \mathrm{~nm}$ were plotted against the corresponding concentrations to construct the calibration graph.

2.3.2. Derivative Ratio Method $\left({ }^{1} D R\right)$. The working standard solutions of TEN were prepared by dilution of TEN stock solution $\left(1000 \mu \mathrm{g} \mathrm{mL}^{-1}\right)$ with distilled water to get a final concentration range of $0.5-40 \mu \mathrm{g} \mathrm{mL}^{-1}$. The absorption spectra of standard TEN solutions were recorded in the wavelength range $200-300 \mathrm{~nm}$ and stored. The stored spectra were divided (amplitude by amplitude at each wavelength) by the spectrum of a standard solution of $20 \mu \mathrm{g} \mathrm{mL}^{-1}$ EMT. The absolute values of the first derivative of the ratio spectra were obtained at $251.5 \mathrm{~nm}$ (number of points $=25$ ), and then plotted against the corresponding concentrations.

2.4. Preparation and Analysis of TEN/EMT Binary Tablets Sample Solution. Truvada tablets were massed and finely powdered. An accurately weighed quantity of the powder 
equivalent to the average weight per tablet was transferred into a beaker containing $50 \mathrm{~mL}$ high purity distilled water. After sonication for $15 \mathrm{~min}$, the content was filtered quantitatively into a $100 \mathrm{~mL}$ volumetric flask and diluted to volume using distilled water. Aliquots of the TEN/EMT binary tablets sample solution were diluted with distilled water to obtain final concentrations within the range $0.5-40 \mu \mathrm{g} \mathrm{mL}^{-1}$ for both drugs (Table 1) and then treated as under "Section 2.3".

\section{Results and Discussion}

3.1. Method Development. The present mixture represents a combination of TEN and EMT. Figure 2 shows the absorption spectra of TEN and EMT and a mixture of both of them at their nominal concentration. As shown in the figure, the UV absorption bands of both drugs are considerably overlapped, showing that the conventional UV method for the assay of TEN is susceptible to interference from EMT. While the UV spectrum of the latter is not greatly affected in the region of 220-280 nm, this is a favorable condition so that conventional zero order or direct first derivative method could be applied for the determination of EMT in the investigated binary mixture. In this context, the first derivative method was found to be more advantageous by virtue of its better sensitivity.

3.1.1. First Derivative Method $\left({ }^{1} D\right)$. The first derivative spectrophotometric method could be applied to resolve such mixture and determine the concentration of EMT in the presence of TEN. Upon examining the first derivative spectra of both drugs, it was found that EMT has a peak at $298.5 \mathrm{~nm}$, while TEN showed no contribution at this wavelength (Figure 3 ). The application of the derivative technique succeeded only in resolving EMT in the presence of TEN through measuring its first derivative peak amplitude at $298.5 \mathrm{~nm}$, where TEN showed no contribution at this wavelength. EMT was determined in the laboratory-prepared mixtures. The results are shown in Table 3.

A recently reported derivative spectrophotometric method [43] claimed that amplitude at $224.38 \mathrm{~nm}$ in the first derivative spectrum was successfully applied to determine TEN in presence of EMT. Examination of Figure 3 indicates that this amplitude at $224.38 \mathrm{~nm}$ is lying at high slope with very poor sensitivity.

Meanwhile, the $1 \mathrm{D}$ to $4 \mathrm{D}$ spectra of TEN were found to be completely overlapped by that of EMT. Hence, in our work derivative ratio spectrum method was applied for the determination of TEN in tablet combination with EMT.

3.1.2. Derivative Ratio Method ( $\left.{ }^{1} D R\right)$. For the determination of TEN, the stored absorption spectra of standard solutions of TEN and solutions of TEN/EMT laboratoryprepared mixtures were divided (amplitude by amplitude at appropriate wavelengths) by the zero-order absorption spectrum of $20 \mu \mathrm{g} \mathrm{mL}^{-1}$ EMT. Then the first derivative of the obtained ratio spectra was calculated (number of points $=25$ ) (Figure 4). The figure shows that several wavelengths could be useful for the determination of TEN; however, only one point was selected for the analysis of TEN (at $251.5 \mathrm{~nm}$ ). This
TABLE 1: Validation data for the determination of TEN and EMT using the proposed spectrophotometric methods.

\begin{tabular}{lcc}
\hline Item & TEN $\left({ }^{1} \mathrm{DR}\right)$ & EMT $\left({ }^{1} \mathrm{D}\right)$ \\
\hline Concentration range $\left.(\mu \mathrm{g} \mathrm{mL})^{-1}\right)$ & $0.5-40$ & $0.5-40$ \\
Correlation coefficient $(r)$ & 0.99999 & 0.99996 \\
Intercept $(a)$ & $2.0 \times 10^{-4}$ & $-3.0 \times 10^{-5}$ \\
$\% y$-intercept & 0.242 & -0.194 \\
Slope $(b)$ & $2.8 \times 10^{-4}$ & $9.0 \times 10^{-4}$ \\
RSD $\%$ of slope & 0.187 & 0.372 \\
$S_{a}$ & $9.0 \times 10^{-5}$ & $5.0 \times 10^{-5}$ \\
$S_{b}$ & $5.0 \times 10^{-5}$ & $3.0 \times 10^{-5}$ \\
$S_{y / x}$ & $2.0 \times 10^{-4}$ & $1.0 \times 10^{-4}$ \\
LOD $\left(\mu \mathrm{g} \mathrm{mL}^{-1}\right)$ & 0.010 & 0.167 \\
LOQ $\left(\mu \mathrm{gLL}^{-1}\right)$ & 0.031 & 0.556 \\
\hline
\end{tabular}

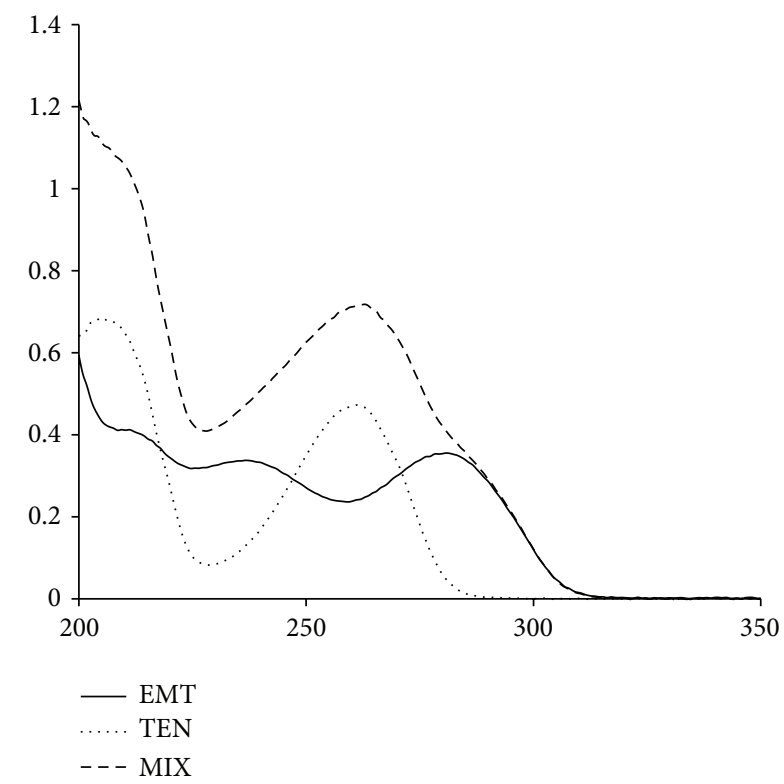

FIGURE 2: Absorption spectra of $1 \mu \mathrm{g} \mathrm{mL}^{-1}$ EMT, $1 \mu \mathrm{g} \mathrm{mL}^{-1}$ TEN, and their mixture in distilled water.

wavelength was chosen on the basis of best recovery values obtained.

3.1.3. Optimization of the Derivative Ratio Spectrophotometric Method. The influence of some instrumental and experimental variables (scan speed, number of points, and divisor concentration) was tested in order to optimize the derivative ratio spectrophotometric method. The influence of scan speed and number of points was studied to obtain the best wavelength interval and best shape of the DR spectra. Noisy spectra were obtained at high scan speed and/or using low number of points. The noise in the spectra decreases as we increase the number of points (at 25) and at medium scan speed.

A study was carried out to test the effect of the divisor concentration (EMT) on the obtained calibration curves, hence the absorption spectra of standard solutions of TEN 


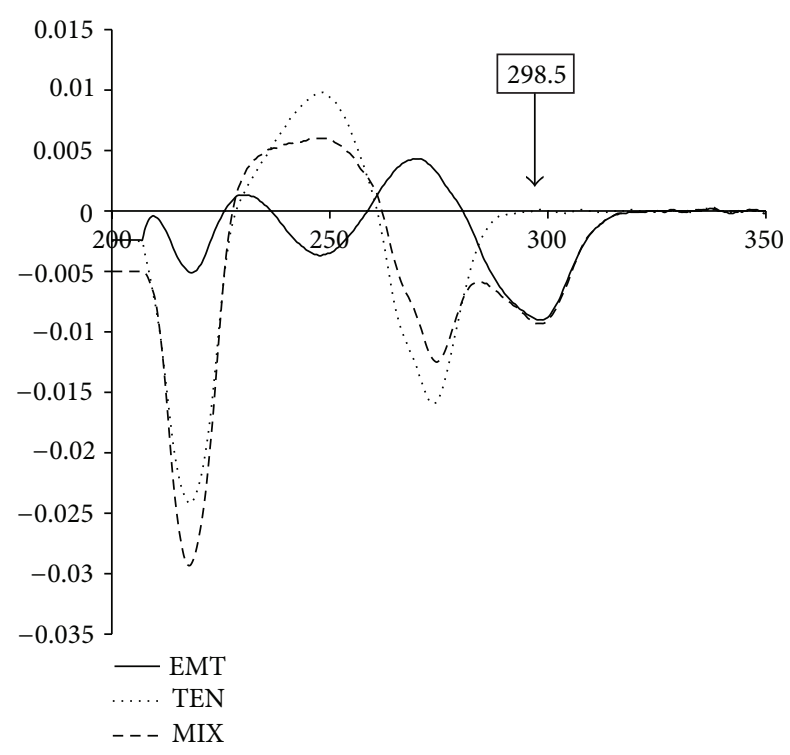

FIGURE 3: First derivative spectra of $1 \mu \mathrm{g} \mathrm{mL}^{-1}$ EMT, $1 \mu \mathrm{g} \mathrm{mL} L^{-1} \mathrm{TEN}$, and their mixture in distilled water.

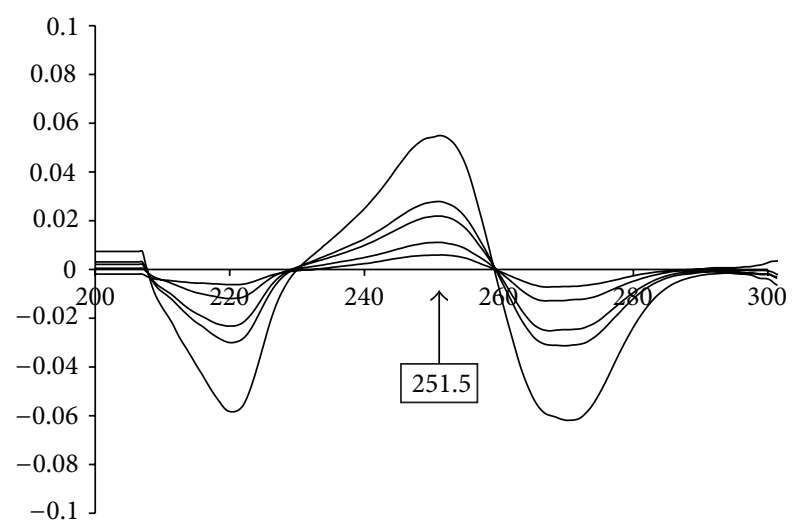

Figure 4: First derivative of ratio spectra of $2,4,8,10$, and $20 \mu \mathrm{g} \mathrm{mL}^{-1}$ TEN using $20 \mu \mathrm{g} \mathrm{mL}^{-1}$ EMT as divisor.

in the concentration range stated in Table 1 were divided by the corresponding amplitudes of standard solutions of EMT $\left(10,15,20\right.$, and $\left.40 \mu \mathrm{g} \mathrm{mL}^{-1}\right)$. The resultant ratio spectra were then differentiated. The derivative ratio value of each solution was measured at the appropriate wavelength and plotted against its concentration. The statistical analysis of these graphs using least squares method shows high values of the correlation coefficients and small values of the intercepts indicating good linearity. The results obtained indicate that the divisor concentration has no effect on the assay.

\subsection{Statistical Analysis of Results}

3.2.1. Concentration Range and Calibration Graph. The linearity of the proposed derivative spectrophotometric procedures was evaluated by analyzing a series of different concentrations for each drug substance. The responses measured at the specified wavelengths were found to be proportional to the drug concentration. Table 1 presents the validation data and statistical parameters for the proposed methods including linear regression equations, concentration ranges, correlation coefficients, standard deviation of the intercept $\left(S_{a}\right)$, the slope $\left(S_{b}\right)$, and standard deviation of residuals $\left(S_{y / x}\right)$. Regression analysis shows good linearity as shown from the correlation coefficient values ( $r>0.9999)$, RSD\% of the slope values which were found less than $0.5 \%$, and the $\% y$-intercept values which were found less than $2 \%$.

Furthermore, in the derivative ratio spectrum method, four different concentrations of the divisor were used in the analysis of standard solutions of TEN. A straight line was obtained in each case. The statistical analysis using least squares method for these assays showed high correlation coefficient values and small values of intercepts proving good linearity.

3.2.2. Detection and Quantitation Limits. According to $\mathrm{ICH}$ guidelines [44], the approach based on the standard error values and the slope of the calibration graph was used for determining the limits of detection and quantitation. The calculated LOD values are $0.010 \mu \mathrm{g} \mathrm{mL}^{-1}$ and $0.167 \mu \mathrm{g} \mathrm{mL}^{-1}$ for TEN and EMT, respectively, while LOQ values are $0.031 \mu \mathrm{g} \mathrm{mL}^{-1}$ and $0.556 \mu \mathrm{g} \mathrm{mL}^{-1}$ for TEN and EMT, respectively.

3.2.3. Accuracy and Precision. The within-day precision and accuracy for the described methods were examined at three concentration levels using three replicate determinations for each concentration through the same day. Similarly, the between-day precision and accuracy were tested by analyzing the same three concentrations for each drug substance using three replicate determinations repeated on 3 days. Recoveries were calculated using the corresponding regression equations, and the results were satisfactory (Table 2). The RSD\% and relative error (Er) did not exceed $2 \%$, proving the high repeatability and accuracy of the developed methods for the estimation of both analytes in their bulk form.

3.2.4. Selectivity. Method selectivity was examined by preparing several laboratory-prepared mixtures of the two compounds at different concentrations within the linearity ranges mentioned in Table 1. These mixtures had ratios both above and below the normal ratio expected in the tablets. The laboratory-prepared mixtures were analyzed according to the previously described conditions for each method. The recovery values, the percentage relative standard deviation (RSD\%) and the percentage relative error values (Er\%) stated in Table 3, were satisfactory, thus confirming the selectivity of the methods and demonstrating its capability to resolve and quantify both analytes in different ratios; the ${ }^{1} \mathrm{D}$ or ${ }^{1} \mathrm{DR}$ amplitudes were only a function of the concentration of the component at the specified wavelength and are independent on the concentration of the other component of the mixture. Hence, the results tabulated were satisfactory, indicating the selectivity of the proposed methods. 
TABLE 2: Accuracy and precision of the proposed spectrophotometric methods for analysis of TEN and EMT.

\begin{tabular}{|c|c|c|c|c|c|c|c|}
\hline \multirow[b]{2}{*}{ Analyte } & \multirow[b]{2}{*}{ Nominal value $\left(\mu \mathrm{g} \mathrm{mL}^{-1}\right)$} & \multicolumn{3}{|c|}{ Within-day $(n=9)$} & \multicolumn{3}{|c|}{ Between-day $(n=9)$} \\
\hline & & $\begin{array}{c}\text { Found } \pm \text { SD } \\
\left(\mu \mathrm{g} \mathrm{mL}^{-1}\right)\end{array}$ & RSD (\%) & $\operatorname{Er}(\%)$ & $\begin{array}{l}\text { Found } \pm \mathrm{SD} \\
\left(\mu \mathrm{g} \mathrm{mL}^{-1}\right)\end{array}$ & RSD (\%) & $\operatorname{Er}(\%)$ \\
\hline \multirow{3}{*}{ TEN $\left({ }^{1} \mathrm{DR}\right)$} & 4.0 & $3.93 \pm 0.037$ & 0.932 & -1.801 & $3.94 \pm 0.031$ & 0.798 & -1.407 \\
\hline & 8.0 & $7.89 \pm 0.036$ & 0.461 & -1.398 & $7.85 \pm 0.063$ & 0.802 & -1.852 \\
\hline & 20.0 & $19.90 \pm 0.137$ & 0.692 & -0.513 & $19.86 \pm 0.111$ & 0.559 & -0.695 \\
\hline \multirow{3}{*}{$\operatorname{EMT}\left({ }^{1} \mathrm{D}\right)$} & 0.5 & $0.49 \pm 0.003$ & 0.668 & -1.890 & $0.50 \pm 0.007$ & 1.320 & -0.756 \\
\hline & 8.0 & $7.94 \pm 0.065$ & 0.825 & -0.732 & $7.96 \pm 0.082$ & 1.028 & -0.543 \\
\hline & 40.0 & $39.89 \pm 0.131$ & 0.328 & -0.269 & $40.16 \pm 0.327$ & 0.815 & 0.039 \\
\hline
\end{tabular}

TABLE 3: Determination of TEN and EMT in laboratory-prepared mixtures using the proposed spectrophotometric methods.

\begin{tabular}{lrcccccc}
\hline \multicolumn{2}{c}{ Nominal value $\left(\mu \mathrm{g} \mathrm{mL}^{-1}\right)$} & \multicolumn{2}{c}{ Found $\pm \mathrm{SD}^{\mathrm{a}}\left(\mu \mathrm{g} \mathrm{mL}^{-1}\right)$} & \multicolumn{2}{c}{$\mathrm{RSD}^{\mathrm{b}}$} & \multicolumn{2}{c}{$\%^{\mathrm{c}}$} \\
TEN & EMT & TEN & EMT & TEN & EMT & TEN & 2.028 \\
10.0 & 20.0 & $10.20 \pm 0.08$ & $20.40 \pm 0.08$ & 0.742 & 0.393 & 2.002 \\
10.0 & 30.0 & $10.23 \pm 0.06$ & $30.59 \pm 0.58$ & 0.543 & 1.903 & 2.270 & 1.969 \\
20.0 & 10.0 & $20.29 \pm 0.10$ & $10.30 \pm 0.08$ & 0.507 & 0.778 & 1.426 & 3.046 \\
30.0 & 10.0 & $30.34 \pm 0.18$ & $10.25 \pm 0.16$ & 0.593 & 1.565 & 2.124 & 1.426 \\
30.0 & 20.0 & $30.48 \pm 0.23$ & $20.57 \pm 0.16$ & 0.759 & 0.780 & 2.853 \\
\hline
\end{tabular}

${ }^{\mathrm{a}}$ Mean $\%$ found \pm SD for five determinations.

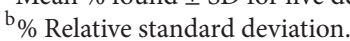

${ }^{c} \%$ Relative error.

3.2.5. Stability of Solutions. The stability of TEN and EMT standard and sample working solutions in water for spectrophotometric analysis was verified during handling by keeping them at room temperature for $6 \mathrm{~h}$. No changes involving the derivative amplitudes in spectrophotometry were noticed. The stock solutions were also stable when kept refrigerated at $4^{\circ} \mathrm{C}$ for at least one week.

3.2.6. Assay of Tablets. The applicability of the proposed derivative methods to the assay of pharmaceutical preparations was examined by analyzing Truvada tablets. Results obtained using the proposed methods (Table 4) were compared to those obtained using a literature-reported spectrophotometric method [38]. The calculated Student's $t$-test and the variance ratio $F$-test results did not exceed the theoretical ones which indicated that there was no significant difference between the investigated methods. Moreover, there was no interference from the excipients present in the pharmaceutical preparation, which indicates the high selectivity of the methods. The good recoveries obtained (Table 4) suggest the good accuracy of the proposed methods.

\section{Conclusions}

The work presented in this paper introduces two spectrophotometric procedures for the determination of TEN and EMT in binary mixture. The derivative spectrophotometric methods are simple, rapid, economic, and environment friendly (green), because no chemical reagents or organic solvents were used. The proposed derivative spectrophotometric methods were advantageous over some reported
TABLE 4: Application of the proposed methods to analysis of TEN and EMT in Truvada tablets.

\begin{tabular}{lcc}
\hline Drug & \multicolumn{2}{c}{ Method } \\
\hline TEN & $\begin{array}{c}\text { Spectrophotometric } \\
\text { methods }^{\mathrm{a}}\end{array}$ & $\begin{array}{c}\text { Comparison } \\
\text { Referee method }\end{array}$ \\
\hline EMT & $100.200 \pm 0.95$ & $100.46 \pm 0.99$ \\
$t^{\mathrm{c}}=0.422, F^{\mathrm{c}}=1.109$ \\
\hline
\end{tabular}

${ }^{\mathrm{a}}$ Mean $\%$ recovery \pm SD for five determinations.

${ }^{\mathrm{b}}$ Reference spectrophotometric method [38].

${ }^{c}$ Theoretical values for $t$ and $F$ at $P=0.05$ are 2.31 and 6.39 , respectively.

spectrophotometric methods for the determination of TEN and EMT in tablets $[37,38]$ by virtue of its better sensitivity (0.5-40 $\mu \mathrm{g} \mathrm{mL}^{-1}$ for both TEN and EMT compared to 4$32 \mu \mathrm{g} \mathrm{mL}^{-1}, 6-48 \mu \mathrm{g} \mathrm{mL}^{-1}$ for TEN and EMT, resp.). Another derivative spectrophotometric method [43] was recently reported, yet it was found to be of poor sensitivity as it measures the first derivative at a high slope of low amplitude for the determination of TEN in presence of EMT.

Therefore, the proposed methods can be recommended for routine analysis and checking quality of the two drugs.

\section{References}

[1] S. C. Sweetman, Ed., Martindale-The Complete Drug Reference, vol. 1, The Pharmaceutical Press, London, UK, 36th edition, 2009. 
[2] A. R. Gennaro, Ed., Remington-The Science and Practice of Pharmacy, Lippincott Williams \& Wilkins, Baltimore, Md, USA, 21st edition, 2005.

[3] A. C. Moffat, M. D. Osselton, and B. Widdop, Clark's Analysis of Drugs and Poisons, vol. 2, The Pharmaceutical Press, London, UK, 3rd edition, 2004.

[4] M. C. Sharma, S. Sharma, and A. D. Sharma, "Hydrotropic solubilization phenomenon spectrophotometric estimation of Tenofovir disoproxil fumarate tablet," Journal of Chemical and Pharmaceutical Research, vol. 2, no. 2, pp. 411-415, 2010.

[5] G. Gnanarajan, A. K. Gupta, V. Juyal, P. Kumar, P. K. Yadav, and P. Kailash, "A validated method for development of tenofovir as API and tablet dosage forms by UV spectroscopy," Journal of Young Pharmacists, vol. 1, no. 4, pp. 351-353, 2009.

[6] A. Shirkhedkar Atul, H. Bhirud Charushila, and J. Surana Sanjay, "Application of UV-spectrophotometric methods for estimation of tenofovir disoproxil fumarate in tablets," Pakistan Journal of Pharmaceutical Sciences, vol. 22, no. 1, pp. 27-29, 2009.

[7] A. Shirkhedkar Atul, H. Bhirud Charushila, and J. Surana Sanjay, "Determination of tenofovir in pharmaceutical formulation by zero order and first order derivative UV-spectrophotometry methods," Research Journal of Chemistry and Environment, vol. 12, no. 1, pp. 49-50, 2008.

[8] A. A. Shirkhedkar, C. H. Bhirud, and S. J. Surana, "Determination of tenofovir in tablets by UV spectrophotometric and derivative spectrophotometric methods," Oriental Journal of Chemistry, vol. 23, no. 3, pp. 1115-1118, 2007.

[9] K. V. Prakash, M. Padmalatha, and E. Dopadally, "Extractive spectrophotometric determination of tenofovir," Biosciences Biotechnology Research Asia, vol. 7, no. 1, pp. 445-448, 2010.

[10] S. M. Mallipatil, S. Noola, M. A. Nandedkar, P. S. Sarsambi, and A. Sonawane, "Spectrophotometric determination of tenofovir disoproxil fumarate," International Journal of Chemical Sciences, vol. 8, no. 2, pp. 977-982, 2010.

[11] M. Majumder, B. Gopinath, G. Koni, and S. K. Singh, "New spectrophotometric determination of tinofovir in bulk and pharmaceutical dosage form," E-Journal of Chemistry, vol. 6, no. 2, pp. 537-540, 2009.

[12] N. Appala Raju, J. Venkateswara Rao, K. Vanitha Prakash, and K. Mukkanti, "Spectrophotometric estimation of tenofovir in pharmaceutical formulations," Biosciences Biotechnology Research Asia, vol. 5, no. 1, pp. 439-442, 2008.

[13] S. O. Choi, N. Rezk, J. S. Kim, and A. D. M. Kashuba, "Development of an LC-MS method for measuring TNF in human vaginal tissue," Journal of Chromatographic Science, vol. 48, no. 3, pp. 219-223, 2010.

[14] M. Yadav, T. Mishra, P. Singhal, S. Goswami, and P. S. Shrivastav, "Rapid and specific liquid chromatographic tandem mass spectrometric determination of tenofovir in human plasma and its fragmentation study," Journal of Chromatographic Science, vol. 47, no. 2, pp. 140-148, 2009.

[15] P. B. Kandagal, D. H. Manjunatha, J. Seetharamappa, and S. S. Kalanur, "RP-HPLC method for the determination of tenofovir in pharmaceutical formulations and spiked human plasma," Analytical Letters, vol. 41, no. 4, pp. 561-570, 2008.

[16] M. Takahashi, Y. Kudaka, N. Okumura, A. Hirano, K. Banno, and T. Kaneda, "Determination of plasma tenofovir concentrations using a conventional LC-MS method," Biological and Pharmaceutical Bulletin, vol. 30, no. 9, pp. 1784-1786, 2007.

[17] C. Bennetto-Hood, M. C. Long, and E. P. Acosta, "Development of a sensitive and specific liquid chromatography/mass spectrometry method for the determination of tenofovir in human plasma," Rapid Communications in Mass Spectrometry, vol. 21, no. 13, pp. 2087-2094, 2007.

[18] T. King, L. Bushman, J. Kiser et al., "Liquid chromatographytandem mass spectrometric determination of tenofovirdiphosphate in human peripheral blood mononuclear cells," Journal of Chromatography B, vol. 843, no. 2, pp. 147-156, 2006.

[19] T. Delahunty, L. Bushman, and C. V. Fletcher, "Sensitive assay for determining plasma tenofovir concentrations by LC/MS/MS," Journal of Chromatography B, vol. 830, no. 1, pp. 6-12, 2006.

[20] D. Ashenafi, V. Chintam, D. Van Veghel, S. Dragovic, J. Hoogmartens, and E. Adams, "Development of a validated liquid chromatographic method for the determination of related substances and assay of tenofovir disoproxil fumarate," Journal of Separation Science, vol. 33, no. 12, pp. 1708-1716, 2010.

[21] Z. Ahmed, S. K. Shetty, B. Gopinath, M. Ahmed, and B. K. Sridhar, "Development and validation of RP-HPLC method for the determination of tenofovir disoproxil in bulk and in pharmaceutical formulation," International Journal of Chemical Sciences, vol. 7, no. 4, pp. 2447-2458, 2009.

[22] S. M. Malipatil and M. A. Nandedkar, "Determination of Tenofovir disoproxil fumarate by a sensitive simple isocratic RP HPLC method," Journal of Indian Council of Chemists, vol. 26, no. 1, pp. 67-69, 2009.

[23] S. Notari, A. Bocedi, G. Ippolito et al., "Simultaneous determination of 16 anti-HIV drugs in human plasma by highperformance liquid chromatography," Journal of Chromatography B, vol. 831, no. 1-2, pp. 258-266, 2006.

[24] A. Peepliwal and C. G. Bonde, "Determination of emtricitabine in human plasma by RP-HPLC with UV-detection," Journal of Pharmacy Research, vol. 3, no. 8, pp. 1712-1715, 2010.

[25] J. A. H. Droste, R. E. Aarnoutse, and D. M. Burger, "Determination of emtricitabine in human plasma using HPLC with fluorometric detection," Journal of Liquid Chromatography and Related Technologies, vol. 30, no. 18, pp. 2769-2778, 2007.

[26] H. Rebiere, B. Mazel, C. Civade, and P.-A. Bonnet, "Determination of 19 antiretroviral agents in pharmaceuticals or suspected products with two methods using high-performance liquid chromatography," Journal of Chromatography B, vol. 850, no. 12, pp. 376-383, 2007.

[27] M. Pendela, D. A. Mamade, J. Hoogmartens, A. Van Schepdael, and E. Adams, "Characterization of emtricitabine related substances by liquid chromatography coupled to an ion trap mass spectrometer," Talanta, vol. 82, no. 1, pp. 125-128, 2010.

[28] D. Ashenafi, A. Verbeek, J. Hoogmartens, and E. Adams, "Development and validation of an LC method for the determination of emtricitabine and related compounds in the drug substance," Journal of Separation Science, vol. 32, no. 11, pp. 18231830, 2009.

[29] U. Seshachalam, B. Haribabu, and K. B. Chandrasekhar, "Development and validation of a stability-indicating liquid chromatographic method for determination of emtricitabine and related impurities in drug substance," Journal of Separation Science, vol. 30, no. 7, pp. 999-1004, 2007.

[30] V. R. Robledo and W. F. Smyth, "A study of the analytical behaviour of selected new molecular entities using electrospray ionisation ion trap mass spectrometry, liquid chromatography, gas chromatography and polarography and their determination in serum at therapeutic concentrations," Analytica Chimica Acta, vol. 623, no. 2, pp. 221-230, 2008.

[31] N. L. Rezk, R. D. Crutchley, and A. D. M. Kashuba, "Simultaneous quantification of emtricitabine and tenofovir in human 
plasma using high-performance liquid chromatography after solid phase extraction," Journal of Chromatography B, vol. 822, no. 1-2, pp. 201-208, 2005.

[32] N. A. Gomes, V. V. Vaidya, A. Pudage, S. S. Joshi, and S. A. Parekh, "Liquid chromatography-tandem mass spectrometry (LC-MS/MS) method for simultaneous determination of tenofovir and emtricitabine in human plasma and its application to a bioequivalence study," Journal of Pharmaceutical and Biomedical Analysis, vol. 48, no. 3, pp. 918-926, 2008.

[33] A. Karunakaran, K. Kamarajan, and V. Thangarasu, "A validated RP-HPLC method for simultaneous estimation of emtricitabine and tenofovir disoproxil fumarate in pure and in tablet dosage form," Pharmacia Sinica, vol. 1, no. 2, pp. 52-60, 2010.

[34] R. Sharma and P. Gupta, "A validated RP-HPLC method for simultaneous estimation of emtricitabine and tenofovir disoproxil fumarate in a tablet dosage form," Eurasian Journal of Analytical Chemistry, vol. 4, no. 3, pp. 276-284, 2009.

[35] T. Delahunty, L. Bushman, B. Robbins, and C. V. Fletcher, "The simultaneous assay of tenofovir and emtricitabine in plasma using LC/MS/MS and isotopically labeled internal standards," Journal of Chromatography B, vol. 877, no. 20-21, pp. 1907-1914, 2009.

[36] A. D. Avolio, M. Sciandra, M. Siccardi et al., "A new assay based on solid-phase extraction procedure with LC-MS to measure plasmatic concentrations of tenofovir and emtricitabine in HIV infected patients," Journal of Chromatographic Science, vol. 46, no. 6, pp. 524-528, 2008.

[37] K. D. Ingale, A. L. Barhate, A. N. Kale, C. D. Bobade, V. P. Choudhari, and B. S. Kuchekar, "Spectrophotometric estimation of emtricitabine and tenofovir disoproxil fumarate in tablet dosage form by simultaneous equation and absorbance ratio methods," Journal of Pharmaceutical Research, vol. 9, no. 1, pp. 11-13, 2010.

[38] S. A. Ghorpade, M. S. Sali, A. H. Kategaonkar, D. M. Patel, V. P. Choudhari, and B. S. Kuchekar, "Simultaneous determination of emtricitabine and tenofovir by area under curve and dual wavelength spectrophotometric method," Journal of the Chilean Chemical Society, vol. 55, no. 1, pp. 115-117, 2010.

[39] M. Joshi, A. P. Nikalje, M. Shahed, and M. Dehghan, "HPTLC method for the simultaneous estimation of emtricitabine and tenofovir in tablet dosage form," Indian Journal of Pharmaceutical Sciences, vol. 71, no. 1, pp. 95-97, 2009.

[40] M. Yadav, P. Singhal, S. Goswami, U. C. Pande, M. Sanyal, and P. S. Shrivastav, "Selective determination of antiretroviral agents tenofovir, emtricitabine, and lamivudine in human plasma by a LC-MS-MS method for a bioequivalence study in healthy Indian subjects," Journal of Chromatographic Science, vol. 48, no. 9, pp. 704-713, 2010.

[41] T. Le Saux, S. Chhun, E. Rey et al., "Quantification of seven nucleoside/nucleotide reverse transcriptase inhibitors in human plasma by high-performance liquid chromatography with tandem mass-spectrometry," Journal of Chromatography $B$, vol. 865, no. 1-2, pp. 81-90, 2008.

[42] A. Senthilkumar, V. Shankarananth, K. K. Rajasekhar, K. S. Srinivas, R. Manikandan, and G. Kumar, "Method development and method validation for combination of anti-retroviral drugs," Journal of Pharmacy Research, vol. 2, no. 10, pp. 16011605, 2009.

[43] V. P. Choudhari, S. Ingale, S. R. Gite, D. D. Tajane, V. G. Modak, and A. Ambekar, "Spectrophotometric simultaneous determination of tenofovir disoproxil fumarate and emtricitabine in combined tablet dosage form by ratio derivative, first order derivative and absorbance corrected methods and its application to dissolution study," Pharmaceutical Methods, vol. 1, no. 2, pp. 47-52, 2011.

[44] ICH Harmonized Tripartite Guideline, Validation of Analytical Procedures, Text and Methodology, Q2(R1), International Conference on Harmonization, IFPMA, Geneva, Switzerland, 2005. 

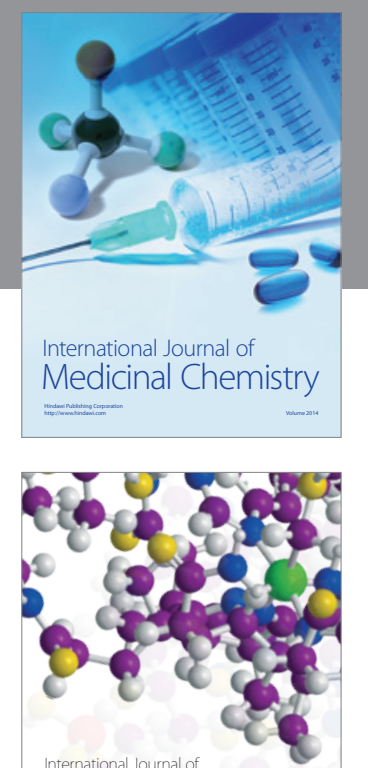

\section{Carbohydrate} Chemistry

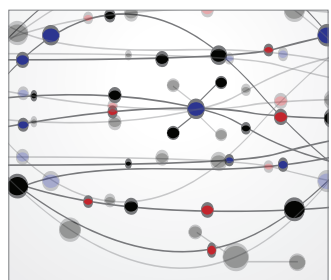

The Scientific World Journal
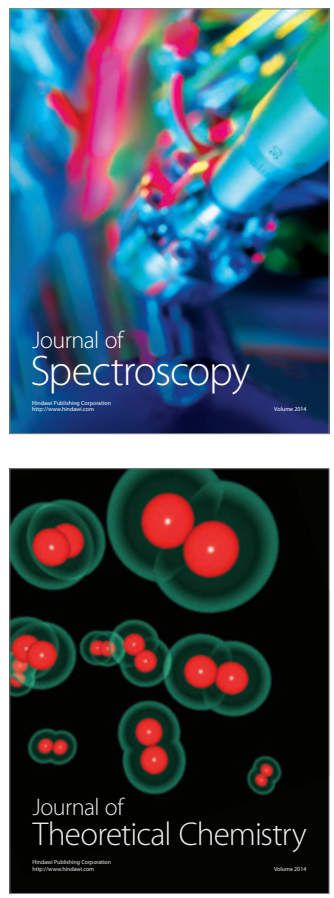
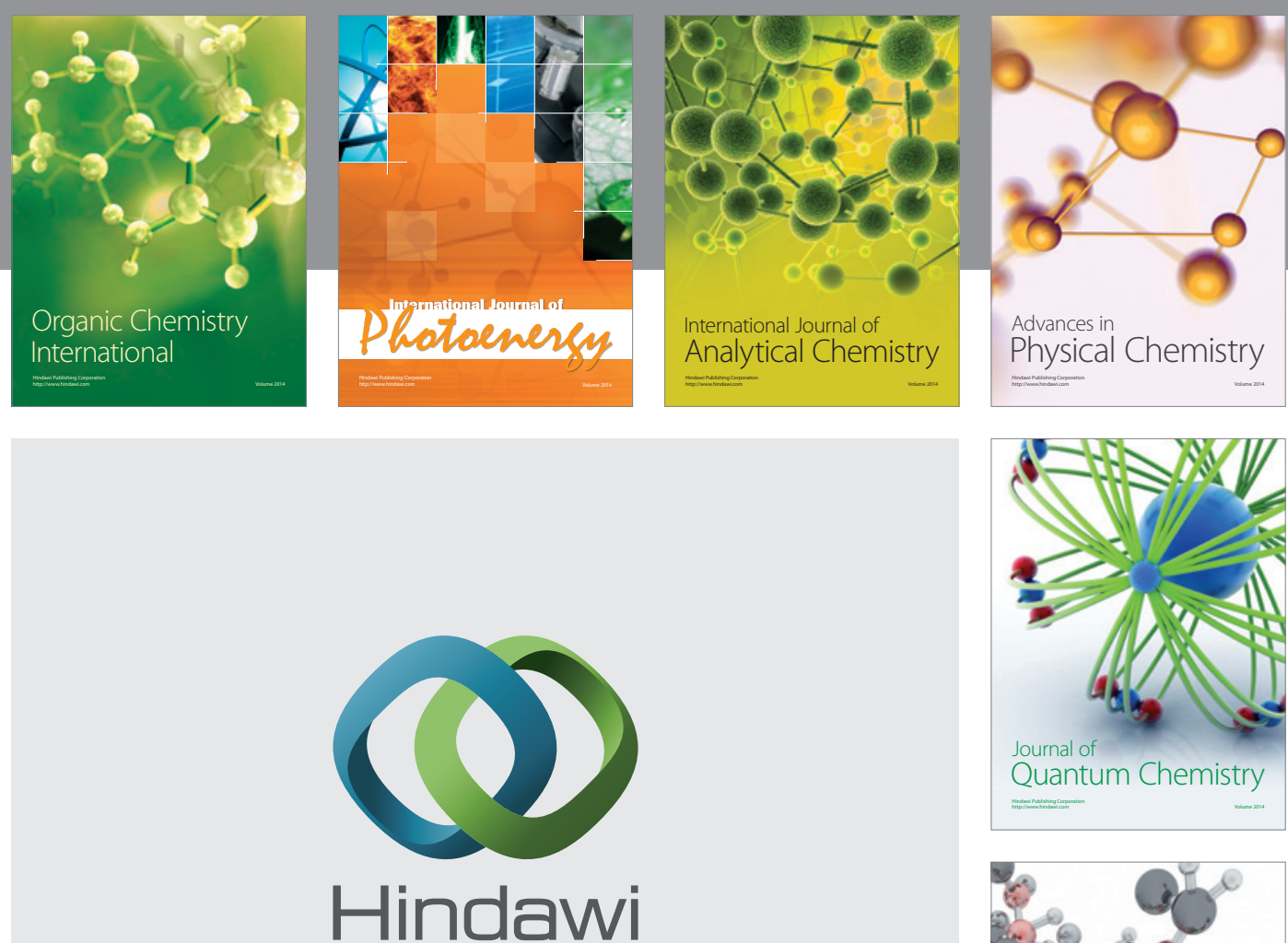

Submit your manuscripts at

http://www.hindawi.com

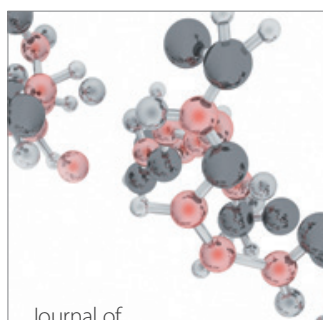

Analytical Methods

in Chemistry

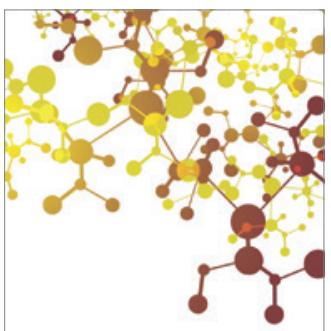

Journal of

Applied Chemistry

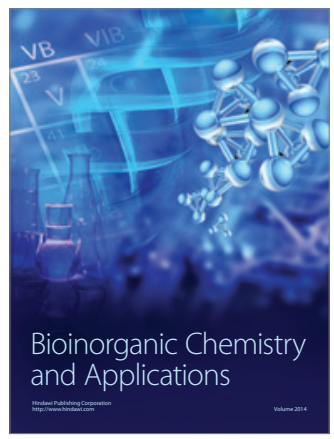

Inorganic Chemistry
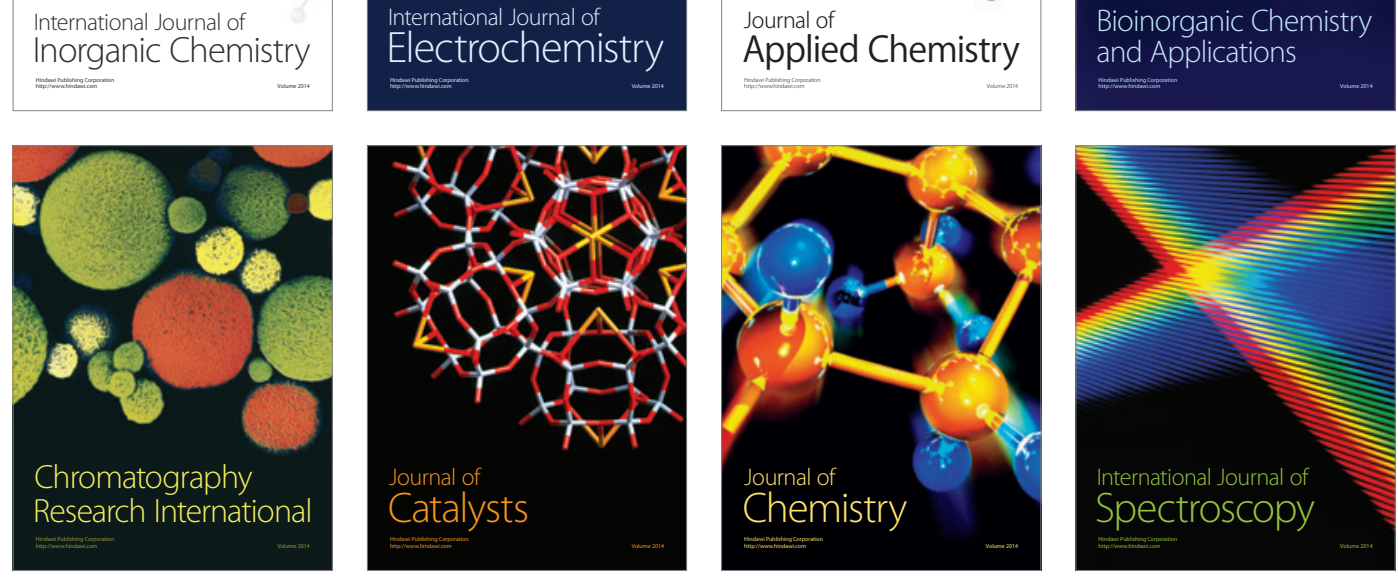